\title{
Real-Time Acceleration Estimation of a Slider Crank Mechanism with an Enhanced Adaptive Windowing Technique
}

\author{
Ergin Kilic ${ }^{1 *}$ \\ 1* Suleyman Demirel University, Faculty of Engineering, Department of Mechanical Engineering, Isparta, Turkey, (ORCID: 0000-0002-3099-0303), \\ erginkilic@sdu.edu.tr
}

(1st International Conference on Applied Engineering and Natural Sciences ICAENS 2021, November 1-3, 2021)

(DOI: 10.31590/ejosat.1008233)

ATIF/REFERENCE: Kilic, E. (2021). Real-Time Acceleration Estimation of a Slider Crank Mechanism with an Enhanced Adaptive Windowing Technique. European Journal of Science and Technology, (28), 506-510.

\begin{abstract}
In this paper, a real-time implementation of a second-order adaptive windowing technique for acceleration estimation is presented for a slider crank mechanism. It is shown that there are some critical parameters which should be carefully set to proper values for a satisfactory acceleration estimation. In this technique, the size of the window is automatically enlarged until the position errors will not be out of the error bands defined by the user. In order to show the effectiveness of the second-order adaptive windowing technique in real-time, a test setup composed of a slider-crank mechanism is used. In the performed tests, only the crank angle is measured via an incremental encoder having a 1024 pulse per revolution, and then, the slider acceleration is estimated by the help of some kinematic calculations using the outputs of the second-order adaptive windowing technique. The estimated acceleration results are directly compared with an acceleration sensor having a measurement range with $\pm 6 \mathrm{~g}$ with a nominal $0-200 \mathrm{~Hz}$ bandwidth attached on the slider. It is found that the root-mean-square value of the acceleration errors along the entire motion profile is at tolerable level so that this effective acceleration estimation technique could be applied to various on-line robotic applications as a soft sensor.
\end{abstract}

Keywords: Optical encoders, Acceleration sensors, Acceleration estimation, Adaptive windowing technique.

\section{Gelişmiş Uyarlanabilir Pencereleme Tekniği ile bir Krank-Biyel Mekanizmasının Gerçek Zamanlı İvme Tahminlemesi}

$\ddot{O} z$

Bu çalışmada, bir krank-biyel mekanizması için ivme tahmini için ikinci dereceden bir uyarlanabilir pencereleme tekniğinin gerçek zamanlı bir uygulaması sunulmaktadır. Doğru bir ivme tahmini için uygun değerlere dikkatlice ayarlanması gereken bazı kritik parametreler olduğu gösterilmiştir. Bu teknikte pencerenin boyutu, konum hataları kullanıcı tarafından tanımlanan hata bantlarının dışına çıkmayıncaya kadar otomatik olarak büyütülür. İkinci mertebeden uyarlamalı pencereleme tekniğinin etkinliğini gerçek zamanlı olarak gösterebilmek için krank-biyel mekanizmasından oluşan bir test düzeneği kullanılmıştır. Yapılan testlerde, devir başına 1024 darbeye sahip artımlı bir optik kodlayıcı ile krank açısı ölçülmekte olup sonrasında ikinci dereceden uyarlamalı pencereleme tekniği kullanılarak bazı kinematik hesaplamalar yardımıyla kızak uzvunun ivmesi tahmin edilmektedir. Tahmin edilen ivme değerleri, kızağa bağlı 0-200 Hz nominal bant genişliğine ve \pm 6 g ölçüm aralığına sahip bir ivmelenme sensörü ile doğrudan karşılaştırılmaktadır. Tüm hareket profili boyunca ivme hatalarının karekök-ortalama değerinin tolere edilebilir düzeyde olduğu ve dolayısıyla bu etkin ivme tahminleme tekniğinin çeşitli çevrimiçi robotik uygulamalarda bir yumuşak sensor olarak kolaylıkla uygulanabileceği gösterilmiştir.

Anahtar Kelimeler: Optik enkoderler, İvme sensörleri, İvme tahminleme, Uyarlanabilir pencereleme tekniği.

* Corresponding Author: erginkilic@,sdu.edu.tr 


\section{Introduction}

Kinematic information is always needed in force controlled robotic devices having a closed-loop motion control system which depends on position, velocity and acceleration. However, obtaining acceleration by numerically differentiating twice from a position signal coming from optical encoders generally does not give satisfactory results due to the quantized data structure of the sensor. In recent years, it has been one of the popular topics to use some estimation methods as soft sensors instead of expensive acceleration sensors, especially in robotic systems with high degrees of freedom.

Taking a first- and a second order numerical derivative and applying a low-pass filtering is one of the most easily applied techniques on a position signal for velocity and acceleration estimation, but it is well known that this approach suffers from problems such as phase distortion and attenuation. In addition, there are different techniques such as Kalman filters for the prediction of velocity and acceleration in the literature [1], [2]. However, this method requires a discrete-time dynamic model of the encoder as well as a tedious fine-tuning of the filter parameters. Some studies in the literature propose prediction methods based on state variables, but they have limited applications due to their dependence on the complete nonlinear state-space system model [3], [4]. Moreover, some researchers seem to be able to predict acceleration using artificial neural networks at the expense of collecting a huge amount of training data specific to the system under consideration [5]. Also, Tanaka et al. realized the hardware implementing fixed-position technique for the estimation of acceleration using FPGAs in realtime [6]. Besides, it is well known that there are adaptive windowing methods which minimize the position error variance and maximize the estimation accuracy by adjusting the size of the window. A first-order adaptive windowing algorithm was proposed for velocity estimations in [7], and then, a second-order adaptive windowing technique was presented to calculate the acceleration estimations in [8]. A hybrid acceleration estimation algorithm based on a Kalman filter and a first-order adaptive windowing method was proposed and a simulation study using an optical encoder having a 2048 pulse per revolution (ppr) was realized by [9]. In another simulation study, a first order adaptive windowing technique for acceleration estimation was used for a two-mass mechanical vibration suppression system having a 2500 ppr encoder resolution [10]. Although a second-order adaptive windowing technique for acceleration estimation was well introduced in [8], it is seen that recent studies preferred to use first-order adaptive windowing techniques instead of using a second-order one due to its computational complexity.

This study explicitly shows a real-time application of an acceleration estimation for a non-linear slider crank mechanism. Hence, this effective acceleration estimation technique could be applied to various on-line robotic applications having a motion control system which close the feedback loop over optical encoders. It will be seen that there are some critical parameters which should be carefully set to proper values for a satisfactory acceleration estimation. Furthermore, in the previous work presented by [8], motion inputs have been given by a hapticdevice user where the data were stored offline for later use. Especially, the references were generated by using off-line forward-backward filtering of the differentiated position signals of the high resolution encoder (5000 ppr) and then compared against the acceleration estimation results calculated using a low resolution encoder (500 ppr). However, in this study, the estimated acceleration results of a slider-crank mechanism will be directly compared with an acceleration sensor for the first time in the current literature.

\section{Material and Method}

\subsection{Adaptive Windowing Technique}

It was shown in [8] that the estimated velocity $\left(\hat{v}_{k}\right)$ and estimated acceleration $\left(\hat{a}_{k}\right)$ values can be easily calculated from (1) and (2) by the help of quantized position signal values $\left(y_{k}\right)$ captured at discrete-time index $\mathrm{k}$. It is also known that increasing the window size $(n)$ up to a critic value improves the accuracy of the estimated acceleration values, however; using an excessive window size will introduce a significant time delay (phase lag) by the process and degrades the accuracy of calculations with respect to the actual ones $\left(a_{k}\right)$, which will be measured by an acceleration sensor in this study.

$$
\begin{aligned}
& \hat{v}_{k}=\frac{1}{n} \sum_{j=0}^{n-1} \hat{v}_{k-j}=\frac{y_{k}-y_{k-n}}{n T} \\
& \hat{a}_{k}=\frac{1}{n} \sum_{j=0}^{n-1} \hat{a}_{k-j}=\frac{\hat{v}_{k}-\hat{v}_{k-n}}{n T}
\end{aligned}
$$

The objective of the adaptive windowing technique is to choose an optimal windowing size regarding kinematics of the system at hand. For acceleration estimation purpose, a secondorder fitting function on the position data is used as:

$$
\hat{y}_{k-i}=c_{1}(k-i)^{2} T^{2}+c_{2}(k-i) T+c_{3}
$$

where $T$ is the sampling-time and $i$ is the $i^{\text {th }}$ sample before the last sample $k$. Moreover, $c_{1}, c_{2}$ and $c_{3}$ are the parameters which should be found according to the error function defined below:

$$
E=\sum_{i=0}^{n}\left(y_{k-i}-\hat{y}_{k-i}\right)^{2}
$$

where $y_{k-i}$ is the $i^{\text {th }}$ before the last measured position signal which is illustrated in Fig. 1.

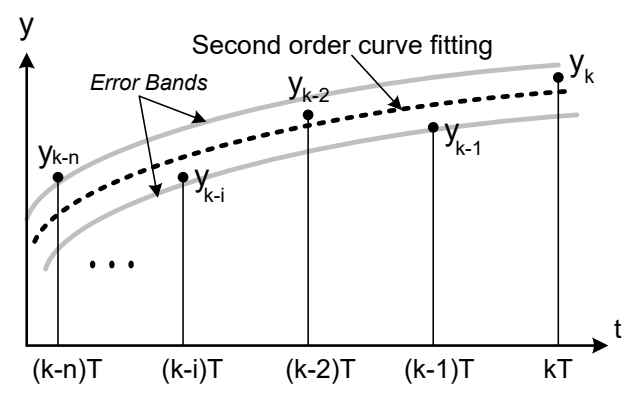

\section{Fig. 1 Curve Fitting of the quantized position signal.}

To obtain optimal results for the $c_{1}, c_{2}$ and $c_{3}$ parameters, the following equations should be solved.

$$
\frac{\partial E}{\partial c_{1}}=0, \frac{\partial E}{\partial c_{2}}=0, \frac{\partial E}{\partial c_{3}}=0
$$

Solution of (5) yields the parameters as below; 


$$
\begin{gathered}
c_{1}=30 \frac{n s_{1}(n-1)-6 n s_{2}+6 s_{3}}{T^{2} n(n-1)(n+1)(n+2)(n+3)} \\
c_{2}=6 \frac{A s_{1}+B s_{2}+C s_{3}}{\operatorname{Tn}(n-1)(n+1)(n+2)(n+3)} \\
c_{3}=3 \frac{D s_{1}+E s_{2}+F s_{3}}{n(n-1)(n+1)(n+2)(n+3)}
\end{gathered}
$$

where the factors in these equations could be given as below;

$$
\begin{aligned}
& s_{1}=\sum_{i=0}^{n} y_{k-i} ; s_{2}=\sum_{i=0}^{n} i \cdot y_{k-i} ; s_{3}=\sum_{i=0}^{n} i^{2} \cdot y_{k-i} \\
& A=3 n\left(2 n^{2}-n-1\right)-10 k n(n-1) \\
& B=-4 n(8 n+1)+6(10 k n+1) \\
& C=30(n-2 k) \\
& D=10 k^{2} n(n-1)-6 k n\left(2 n^{2}-n-1\right)+n\left(3 n^{3}-n-2\right) \\
& E=8 k n(8 n+1)-6 n\left(2 n^{2}-n-1\right)-12 k(5 k n+1) \\
& F=10 n(n-1)+60 k(k-n)
\end{aligned}
$$

It is very important to note that there was a sign error in the writing of parameter $D$ published in [8] (ICSES'10, page 63, first column). It will be shown later how this sign error disrupts the estimation results. Consequently, the following equations are used for the estimation of position, velocity and acceleration.

$$
\begin{aligned}
& \hat{p}_{k}=\hat{y}(k T)=c_{1}(k T)^{2}+c_{2}(k T)+c_{3} \\
& \hat{v}_{k}=\left.\frac{d \hat{y}}{d t}\right|_{t=k T}=2(k T) c_{1}+c_{2} \\
& \hat{a}_{k}=\left.\frac{d^{2} \hat{y}}{d t^{2}}\right|_{t=k T}=2 c_{1}
\end{aligned}
$$

The main purpose of the enhanced adaptive windowing (EAW) method is to find a window of maximum length $(n)$ such that all the position errors are within an error band:

$$
\left|y_{k-i}-\hat{y}_{k-i}\right| \leq d, \quad \forall i \in\{1,2, \ldots, n\}
$$

where $d$ is the upper bound of quantization error.

\subsection{Real-Time Implementation of the EAW}

Although the EAW algorithm may seem computationally intensive, all necessary computations can be conveniently implemented on a Data Acquisition Board (Humusoft ${ }^{\circledR}$ Model: MF624). As could be seen from Fig. 2, a MATLAB/Simulink ${ }^{\circledR}$ diagram was created in which a Delay Line and a Reshape blocks were used to get the position data coming from the Encoder Input block in a line vector form. Delay Line size, which is set to 12 in this study, defines the maximum allowable window size (n) of the EAW technique. $K$ is a constant gain which is used to convert encoder signals from pulse units to degree units. Furthermore, sampling time $(T)$ and the error band limit $(d)$ should also be defined before the calculations performed. Furthermore, Fig. 3 shows the MATLAB function of the EAW algorithm, which will be used for real-time calculations.

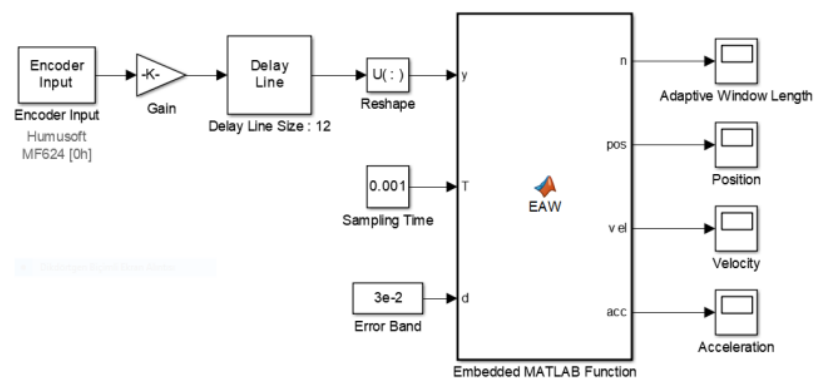

Fig. 2 Real-time implementation of the EAW technique.

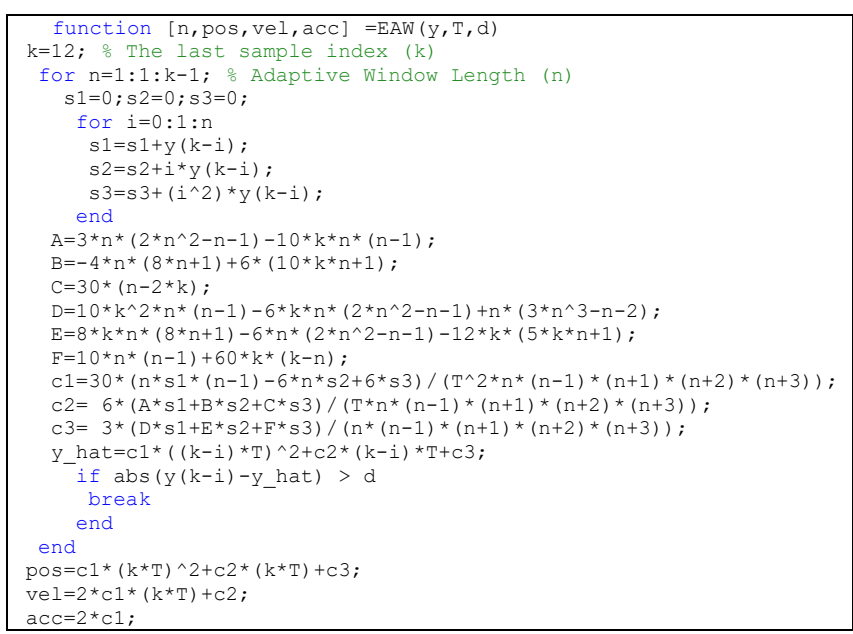

Fig. 3 MATLAB M-File of the EAW technique.

Sampling time is arranged to 0.001 seconds for general purpose. However, it is critical to note that the value of error band $(d)$ is determined via trial and error. If the error band limit is chosen too big, window length $(n)$ will stick to its predetermined maximum value, which is set to 12 in this study. On the other hand, the error band should not be too small as the estimated acceleration values will fluctuate enormously.

\subsection{Experimental Setup}

In this study, a slider crank mechanism presented in Fig 4 is used as an experimental setup. The aim of the study is to estimate the slider acceleration from the position information of the crank. For this purpose, an optical encoder with $1024 \mathrm{ppr}$ is used to measure the crank angle $\theta$ which is schematically represented in Fig. 5. Moreover, an acceleration sensor is placed on the slider in order to measure the slider acceleration $(\ddot{s})$. Therefore, the acceleration estimation performance of the EAW technique will be directly compared with an acceleration sensor (TE connectivity ${ }^{\circledR}$ Model:4033-006-120). Acceleration range of this sensor is $\pm 6 \mathrm{~g}$ with a nominal $0-200 \mathrm{~Hz}$ bandwidth.

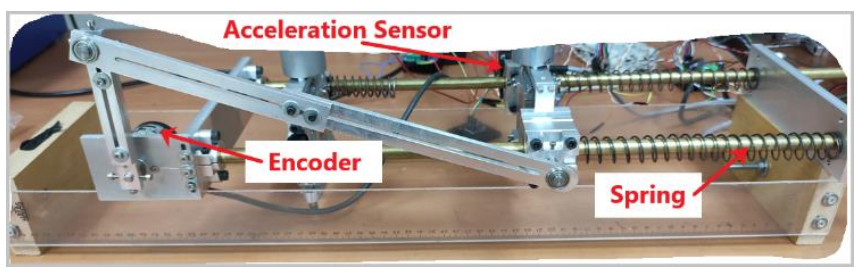

Fig. 4 Experimental setup. 


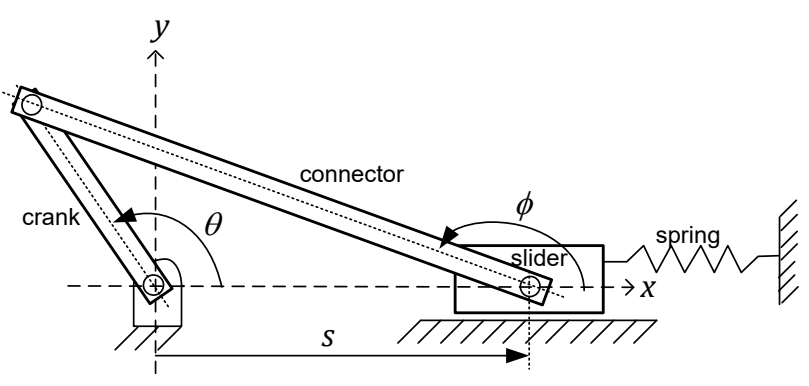

Fig.5 Schematic of the slider-crank mechanism.

Since the purpose of this study is to calculate slider acceleration without using any acceleration sensor, one should perform some kinematic calculations in order to achieve the position $(s)$, velocity $(\dot{s})$ and acceleration $(\ddot{s})$ of the slider with only using the position information of the crank $(\theta)$. Therefore, the following trigonometric equations could be written for this mechanism in $\mathrm{x}-$ y directions as:

$$
\begin{gathered}
a_{2} \cdot \cos \theta=s+a_{3} \cdot \cos \phi \\
a_{2} \cdot \sin \theta=a_{3} \cdot \sin \phi
\end{gathered}
$$

where $a_{2}$ is the length of the crank (105 mm) and $a_{3}$ is the length of the connector $(326 \mathrm{~mm})$. In addition, using the first and second derivatives of (15) and (16), the following kinematic equations can be obtained with the help of the velocity and acceleration influence coefficients $\left(g_{1}, g_{2}\right.$ and $\left.h_{2}\right)$ determined for a slidercrank mechanism [11].

$$
\begin{gathered}
\phi=\sin ^{-1}\left(\frac{a_{2}}{a_{3}} \cdot \sin \theta\right) \\
g_{1}=\frac{a_{2}}{a_{3}} \cdot \frac{\cos \theta}{\cos \phi} ; g_{2}=a_{2} \cdot \frac{\sin (\phi-\theta)}{\cos \phi} \\
h_{2}=a_{2} \cdot \frac{-\cos (\phi-\theta) \cdot \cos \phi+\cos \theta \cdot g_{1}}{\cos \phi^{2}} \\
s=a_{2} \cdot \cos \theta-a_{3} \cdot \cos \phi \\
\dot{s}=\left[g_{2}\right] \cdot \dot{\theta} \\
\ddot{s}=\left[g_{2}\right] \cdot \ddot{\theta}+\left[h_{2}\right] \cdot \dot{\theta}^{2}
\end{gathered}
$$

Consequently, the equations (20), (21) and (22) can be conveniently used to calculate the position, velocity and acceleration of the slider. As could be seen, the position, velocity and the acceleration of the crank angle $(\theta, \dot{\theta}$ and $\ddot{\theta})$ are needed instantly in the kinematic calculations of the slider; however, only the position of the crank was measured directly. Please note that, acceleration sensor attached on the slider will only be used for the verification purposes. Fig. 6 shows the MATLAB/Simulink diagram used both for the measurement and estimation of the slider acceleration in real-time.

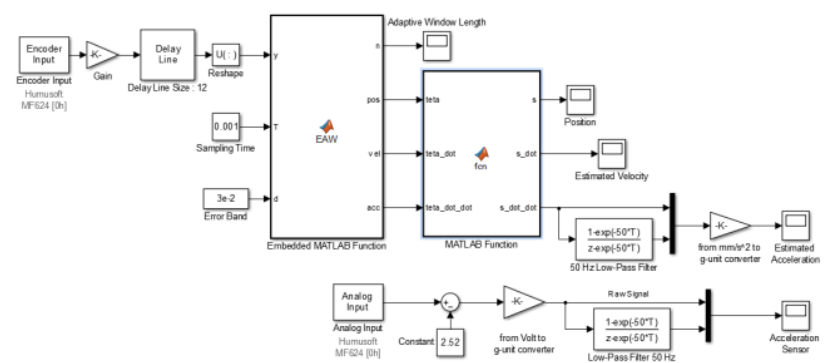

Fig.6 Real-time acceleration estimation for the slider-crank mechanism.

\section{Results and Discussion}

The initial position of the crank is exactly at $90^{\circ}$ when the mechanism is at equilibrium due to the spring connected to the slider. The slider is then allowed to free vibration by adjusting the crank initial position from $90^{\circ}$ to $130^{\circ}$ by hand as shown in Fig 7 . The acceleration of the slider measured by the acceleration sensor for this crank motion is given in Fig 8. As could be seen, there are extreme fluctuations in the raw sensor signal due to the excessive roughness involved in the linear guide system. To obtain a smooth acceleration results in this work, a low-pass filtering (with a cutoff frequency $50 \mathrm{~Hz}$ ) is applied on the measured acceleration signal.

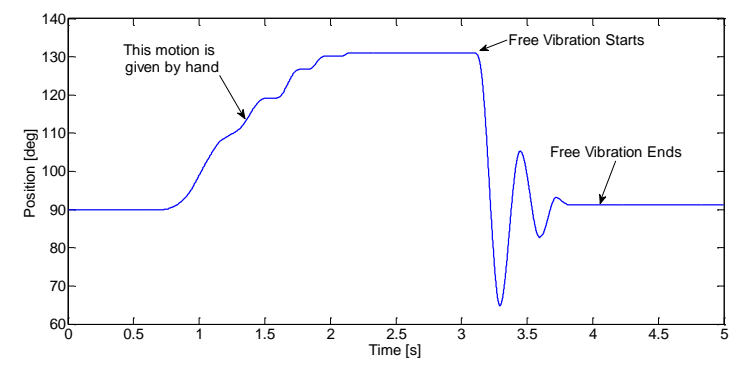

Fig. 7 Measured crank position profile.

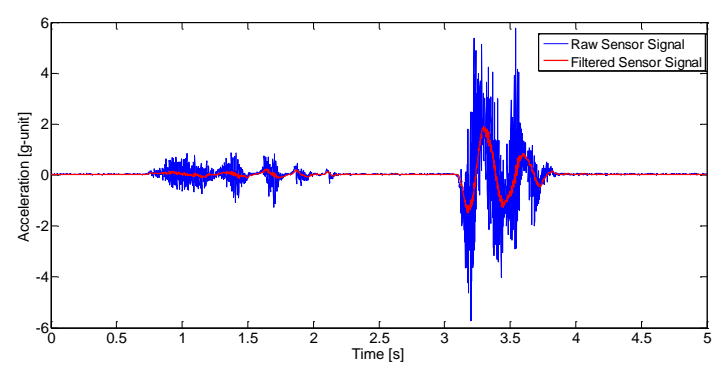

Fig.8 Measured and Low-pass filtered acceleration sensor data.

Fig. 9. compares the performance of the EAW technique for acceleration estimation with the values measured by the acceleration sensor. Also, Fig. 10 shows low-pass $(50 \mathrm{~Hz})$ filtered versions of the signals which are presented in Fig. 9. As could be seen there is not any problem such as phase distortion or attenuation in acceleration estimates. The rms value of errors between the filtered acceleration signals along the entire motion profile is calculated as $0.0807 \mathrm{~g}$-unit (or $0.7916 \mathrm{~m} / \mathrm{s}^{2}$ ). 


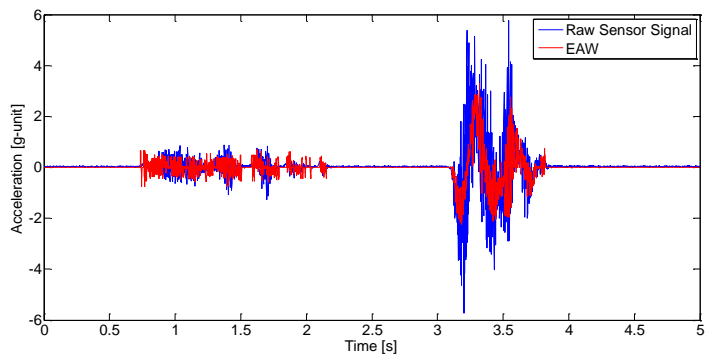

Fig.9 Comparison of EAW technique with the acceleration sensor

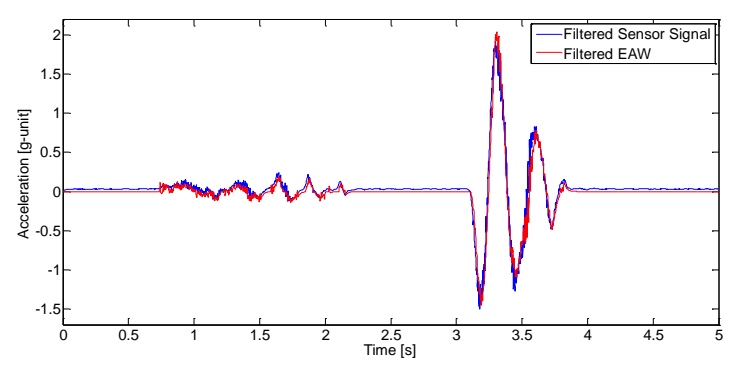

Fig. 10 Low-pass filtered acceleration data

As it is remembered, there was a sign error in the D parameter of the EAW technique published in [8]. Fig. 11 shows how this small sign error distorts the estimated acceleration values. Therefore, all the equations of the EAW technique should be checked twice and implemented carefully.

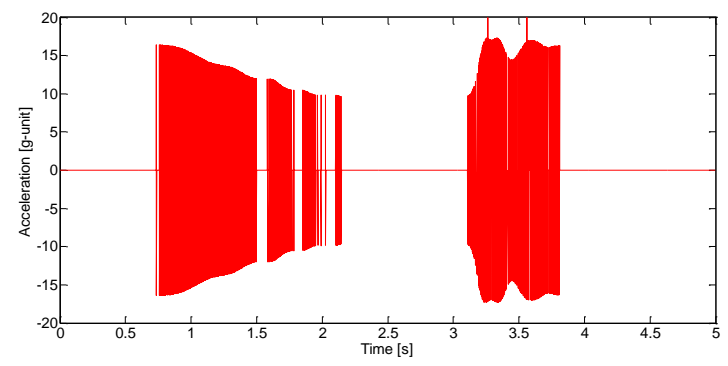

Fig. 11 Acceleration estimation results when there was a sign error in parameter $D$

\section{Conclusions and Recommendations}

This study presented the real-time implementation of the developed second-order adaptive windowing technique for acceleration estimation on a crank-slider mechanism. The crank angle was measured by the help of an optical encoder with 1024 ppr and this position signal is used to estimate acceleration of the slider link. Despite its intensive computational burden of the EAW technique, it was shown that the developed algorithm could be easily implemented on a Data Acquisition Board with using a $1000 \mathrm{~Hz}$ sampling frequency. The performance of the EAW technique has been evaluated with an experimental study and it has been shown that the acceleration estimation errors are found to be acceptable/tolerable for many industrial robotic applications. In addition, the proposed acceleration estimation method can be conveniently used as a soft sensor in case of acceleration sensor failures in many robotic systems.

\section{References}

[1] Jeon, S. and Tomizuka, M. (2007). Benefits of acceleration measurement in velocity estimation and motion control. Control Engineering Practice, 15(3), 325-332.

[2] Belanger, P. R., Dobrovolny, P., Helmy, A. and Zhang, X. (1998). Estimation of angular velocity and acceleration from shaft-encoder measurements. Int. J. Robot. Res., 17(11), 1225-1233.

[3] Lorenz, R.D. and Van Pattern, K.W. (1991). HighResolution Velocity Estimation for All-Digital ac Servo Drives. IEEE Transactions on Industry Applications, 27(4), 701-705.

[4] Brunsbach, B.J., Henneberger, G. and Klepsch, T. (1992). Speed Estimation with Digital Position Sensor. Proceedings of the International Conference on Electrical Machines (ICEM'92), p. 577-581.

[5] Gao, X.Z. and Ovaska, S.J. (2001). Acceleration signal estimation using neural networks. Meas. Sci. Technol., 12(10), 1611-1619.

[6] Tanaka, H., Nishi, H. and Ohnishi, K. (2008) .An Approach to Acceleration Estimation Using FPGA. IEEE International Symposium on Industrial Electronics, p. 19591964.

[7] Janabi-Sharifi, F., Hayward, V., and Chen, C.J. (2000). Discrete-Time Adaptive Windowing for Velocity Estimation. IEEE Transactions on Control Systems Technology, 8(6), 1003-1009.

[8] Kilic, E., Baser, O., Dolen, M. and Konukseven, E.I. (2010). An Enhanced Adaptive Windowing Technique for Velocity and Acceleration Estimation using Incremental Position Encoders. The International Conference on Signals and Electronic Systems (ICSES'10), p. 61-64.

[9] Jin, J. and Pang, Q. (2014). A novel accelaration estimation algorithm based on Kalman filter and adaptive windowing using low-resolution optical encoder. IEEE International Conference on Control Science and Systems Engineering, p. 185-189.

[10] Jin, J. and Huang, S. (2014). A novel accelaration estimation algorithm for mechanical vibration suppression of two-mass system. 17th International Conference on Electrical Machines and Systems, p. 2066-2070.

[11] Soylemez, E. (2009). Mechanisms, 4th ed., Ankara, Turkey: Middle East Technical University. 